\title{
High IGFBP2 Expression Correlates with Tumor Severity in Pediatric Rhabdomyosarcoma
}

\author{
Lucia Tombolan, ${ }^{*}$ Francesca Orso, ${ }^{\dagger \neq \S}$ \\ Vincenza Guzzardo," Silvia Casara, ${ }^{*}$ \\ Angelica Zin," Massimo Bonora, ${ }^{* *}$ \\ Chiara Romualdi, ${ }^{*}$ Carlotta Giorgi, ${ }^{* *}$ \\ Gianni Bisogno," Rita Alaggio," Paolo Pinton, ** \\ Cristiano De Pittà, ${ }^{*}$ Daniela Taverna, ${ }^{\dagger \neq \S}$ \\ Angelo Rosolen," and Gerolamo Lanfranchi* \\ From the Department of Biology and the Interdepartmental \\ Research Center in Innovative Biotechnology (CRIBI),* and the \\ Departments of Medical and Diagnostic Sciences and Special \\ Therapies, " and Paediatric Hematology and Oncology," Padova \\ Hospital, University of Padova, Padova; the Department of \\ Oncological Sciences, ${ }^{\dagger}$ the Molecular Biotechnology Center, ${ }^{\ddagger}$ and \\ the Center for Complex Systems in Molecular Biology and \\ Medicine, ${ }^{\S}$ University of Torino, Torino; and the Department of \\ Experimental and Diagnostic Medicine, ${ }^{* *}$ the Section of General \\ Pathology, Interdisciplinary Center for the Study of \\ Inflammation, Laboratory for Technologies of Advanced \\ Therapies, University of Ferrara, Ferrara, Italy
}

Rhabdomyosarcoma (RMS) is the most common childhood sarcoma and is identified as either the embryonal or alveolar (ARMS) subtype. In approximately $75 \%$ of cases, ARMSs are characterized by specific chromosomal translocations that involve $P A X$ and $F K H R$ genes. ARMS gene expression signatures vary, depending on the presence or absence of the translocations. Insulin-like growth factor-binding protein 2 (IGFBP2) is strongly overexpressed in translocation-negative RMS. Because IGFBP2 is associated with tumorigenesis, we investigated its functional role in RMS. An analysis of IGFBP2 distribution in RMS cell lines revealed a strong accumulation in the Golgi complex, in which morphological characteristics appeared peculiarly modified. After silencing IGFBP2 expression, our microarray analysis revealed mostly cell cycle and actin cytoskeleton gene modulations. In parallel, IGFBP2-silenced cells showed reduced cell cycle and rates of invasion and decreased seeding in the lungs after tail vein injections in immunodeficient mice. An analysis of IGFBP2 mRNA and protein localization in human tumors showed abnormal protein accumulation in the Golgi complex, mostly in $P A X / F K H R$-negative RMS. Moreover, an analysis of patients with RMS revealed the presence of conspicuous circulating levels of IGFBP2 proteins in children with highly aggressive RMS tumors. Taken together, our data provide evidence that IGFBP2 contributes to tumor progression and that it could be used as a marker to better classify clinical and biological risks in RMS. (Am J Patbol 2011, 179:2611-2624; DOI: 10.1016/j.ajpath.2011.07.018)

Insulin-like growth factor-binding proteins (IGFBPs) are a family of six serum proteins that bind IGFs, thus modulating the availability and interactions of these growth factors with their receptors. The $36-\mathrm{kDa}$ IGFBP2 is the second most abundant IGF-binding protein, being highly expressed in the fetus and in several tissues and biological fluids of the adult. ${ }^{1}$ Both stimulatory and inhibitory effects of IGFBP2 on IGF signaling have been reported, but its biological pathways and mechanisms have not been fully elucidated. IGFBP2 binds extracellular matrix proteins, most likely via its heparin-binding domain or its distinctive integrin-interaction arg-gly-asp motif. ${ }^{2}$ The association of IGFBP2 with cell surface probably modulates cell function in two ways: by affecting the bioavailability of IGFs in the pericellular space, thereby regulating receptor targeting of IGFs, and by a direct IGF-independent action on cell signaling pathways. ${ }^{3,4}$

\footnotetext{
Supported by grants from the Italian Association for Cancer Research (AIRC) (2008/6014; 2010-IG 10476 to P.P.; 2010-IG 10104 to D.T.); Fondazione Città della Speranza ONLUS, Padova, Italy; a grant from Fondazione Telethon (GGP09128); Compagnia di San Paolo (D.T.); and a grant from FIRB giovani 2008 (RBFR08F2FS-002 to F.O.). Lucia Tombolan is a PostDoc Fellow of the University of Padova.

Accepted for publication July 26, 2011

Supplemental material for this article can be found at $h t t p: / / a j p$. amjpathol.org or at doi: 10.1016/j.ajpath.2011.07.018

Address reprint requests to Gerolamo Lanfranchi, M.S., Department of Biology and Interdepartmental Research Center in Innovative Biotechnology (CRIBI), University of Padova, Via Ugo Bassi 58/b, 35151 Padova, Italy; or Angelo Rosolen, M.D., Department of Paediatric Hematology and Oncology, Padova Hospital, University of Padova, Via Giustiniani 3, 35128 Padua, Italy. E-mail: gerolamo.lanfranchi@unipd.it or angelo.rosolen@ unipd.it.
} 
Although the effects of IGFBP2 vary depending on cell model, this protein is involved in several important cellular processes, such as proliferation, cell migration, and adhesion, all of which play key roles in cancer establishment and progression.

Overexpression of IGFBP2 in neuroblastoma cells and its interaction with components of the pericellular and extracellular matrices result in local sequestration of IGF1 and then in a dramatic enhancement of cell proliferation. ${ }^{5}$ In contrast, the interaction of IGFBP2 with integrin $\alpha 5 \beta 1$ produces an antiproliferative effect. ${ }^{4}$ Pereira et al ${ }^{6}$ proposed that the interaction between $\alpha \vee \beta 3$ integrin and IGFBP2 negatively modulates IGF-mediated cellular migration responses.

The involvement of IGFBP2 in cell migration and adhesion has been extensively studied in human gliomas because consistent IGFBP2 overexpression was discovered in this malignancy. ${ }^{7}$ Signatures of glioma cell lines stably expressing IGFBP2 were compared with parental cells revealing an increased expression of several invasion-related genes, including matrix metalloproteinase (MMP) 2. ${ }^{8,9}$ An independent study ${ }^{10}$ by which the /GFBP2 gene was inactivated in two glioma cell lines indicated that the surface glycoprotein CD24 acted as a candidate downstream target of IGFBP2, promoting invasiveness. Furthermore, IGFBP2 directly interacts with IIp45, an intracellular molecule that appears to antagonize the IGFBP2-induced invasiveness of glioblastoma cells. ${ }^{11}$ Recent studies ${ }^{12,13}$ also suggested an inverse correlation between IGFBP2 and tumor suppressor genes, such as PTEN and p16/INK4, whose loss of function is frequently observed in human cancer. PTEN induces the decrease of IGFBP2 expression, and this effect is mediated by phosphorylation of Akt. ${ }^{14}$

Overall, elevated expression of IGFBP2 has been reported in a variety of tumors, such as glioma, ${ }^{15}$ prostate cancer, ${ }^{16}$ ovarian cancer, ${ }^{17}$ breast cancer, ${ }^{18-20}$ and sarcoma. ${ }^{21,22}$ In many instances, its expression correlates with grade of malignancy. Taken together, these findings suggest that IGFBP2 may participate in the regulation of tumor growth and invasion.

Rhabdomyosarcoma (RMS) is the most common soft tissue sarcoma of childhood, divided into two major histological subtypes: alveolar RMS (ARMS) and embryonal RMS (ERMS). ARMS shows a dismal prognosis, significantly worse than ERMS. ${ }^{23}$ However, it is not known why ARMSs have a greater aggressiveness and metastatic potential than ERMSs. Cytogenetic and molecular analyses have demonstrated that ARMSs frequently harbor the reciprocal chromosomal translocation $\mathrm{t}(2 ; 13)$ in which $P A X 3$ and FKHR genes are juxtaposed and, albeit less commonly, the variant translocation $t(1 ; 13){ }^{24}$ There is also some evidence that PAX3/FKHR-positive ARMSs have a worse prognosis than the PAX3/FKHR-negative counterpart. ${ }^{25,26}$

Knock-in mouse experiments demonstrated that the expression of PAX3/FKHR fusion protein was not able to generate histologically and immunohistochemically (IHC) genuine ARMS at a high frequency, suggesting that PAX3/FKHR protein is necessary, but not sufficient, for tumor initiation. ${ }^{27}$ Moreover, expression profiling stud- ies $^{28,29}$ have shown that the PAXIFKHR gene confers to ARMS an expression signature that is distinct from translocation-negative ARMS and from ERMS. In whole, these findings would suggest that ARMS differs from ERMS and, despite the almost identical morphological appearance, that ARMS is not a single biological, and possibly clinical, entity.

We performed an expression study ${ }^{29}$ on RMS, identifying a series of genes that were differentially expressed in PAX3/FKHR-positive versus PAX3/FKHR-negative ARMS. From a detailed analysis of these genes, IGFBP2 emerged as one of the most interesting overexpressed genes in PAXIFKHR-negative ARMS compared with PAXI FKHR-positive ARMS. Most RMS studies ${ }^{30}$ have focused on the consequences of the PAX/FKHR fusion protein in the activation of a myogenic program, transformation, or cellular growth, but it is unclear which signaling pathways are altered in PAXIFKHR-negative RMS. In the present study, we focused on the role of IGFBP2 as a distinctive overexpressed gene in ARMS and PAXIFKHR-negative ERMS. From in vitro and in vivo experiments using RMS cell lines, we demonstrated the positive role of IGFBP2 in cell cycle progression and invasiveness. A study on a cohort of patients with RMS suggests that IGFBP2 could be used as an $\mathrm{IHC}$ marker to distinguish between $P A X /$ FKHR-positive and PAXIFKHR-negative RMS and as a plasma marker with potential prognostic impact in patients with RMS.

\section{Materials and Methods}

\section{Cell Culture}

Human ARMS cells (RH4, RH28, RH30, and RH18), human ERMS cells (RD, RH36, and SMS-CTR), and mouse C2C12 myoblast cells were maintained in Dulbecco's modified Eagle's medium containing 10\% fetal calf serum, penicillin (100 U/mL), and streptomycin $(100 \mu \mathrm{g} / \mathrm{mL})$ (Invitrogen Life Technologies, Carlsbad, CA) at $37^{\circ} \mathrm{C}$ in $5 \% \mathrm{CO}_{2}$ in a humidified incubator.

The human RMS cell lines RH30 and RD and $\mathrm{C} 2 \mathrm{C} 12$ control cells were obtained from American Type Culture Collection (Manassas, VA); $\mathrm{RH} 4$ and $\mathrm{RH} 18$ were a gift from Dr. Peter J. Houghton (St Jude Children's Hospital, Memphis, TN); and SMS-CTR, RH36, CCA were obtained from Dr. Maria Tsokos (National Cancer Institute, Bethesda, MD).

\section{Tumor Samples}

Selected clinical parameters of patients with RMS used for this analysis are available (see Supplemental Tables S1 and S2 at $h$ ttp://ajp.amjpathol.org).

\section{RNA Interference}

$\mathrm{RH} 36$ cells at $50 \%$ to $70 \%$ confluence were transfected with SMARTpool small-interfering RNA (siRNA) for target gene IGFBP2 (silGFBP2) or with nontargeting siRNA pool (siCONTROL) using Dharmafect 3 transfection reagent 
(Dharmacon; Thermo Scientific, Lafayette, CO). We performed preliminary experiments to achieve the highest efficiency and reproducibility. The efficacy of gene knockdown was evaluated at the mRNA or protein level by using RT-PCR and Western blot analysis after 48 hours.

\section{Real-Time RT-qPCR}

Total RNA was isolated using the TRIzol reagent (Invitrogen Life Technologies) and reverse transcribed using Super-Script II (Invitrogen Life Technologies), according to the manufacturer's instructions. Each total RNA sample was analyzed for quality control by capillary electrophoresis using the RNA 6000 Nano LabChip and the Agilent Bioanalyzer 2100 (Agilent Technologies, Palo Alto, CA). An aliquot of first-strand cDNA was PCR amplified using SYBR Green chemistry (Finnzymes, Espoo, Finland). Quantitative RT-PCR (RT-gPCR) was performed in the Applied Biosystems SDS-7500 thermal cycler (Applied Biosystems, Life Technologies, Foster City, CA). Genespecific primers were designed using Primer3 software (http://frodo.wi.mit.edu/primer3, last accessed July 20, 2008) or Application Design Tools (Roche Applied Science, Monza, Italy). The sequences used are as follows: IGFBP2, 5'-ACTCCCTGCCAACAGGAAC-3' (forward) and 5'-GTTGGGGTTCACACACCAG-3' (reverse); glyceraldehyde-3-phosphate dehydrogenase (GADH), 5'-TCCTCTGACTTCAACAGCGA-3' (forward) and 5'GGGTCTTACTCCTTGGAGGC-3' (reverse); and guanine nucleotidebinding protein, beta-peptide 2-like 1 (GNB2L1), 5'-GGGTCTTACTCCTTGGAGGC 3' (forward) and 5'-GCTTGCAGTTAGCCAGGTTC-3' (reverse).

By using SYBR Green chemistry, we performed the dissociation curve to confirm the specificity of the amplicon. Cycling parameters consisted of an initial denaturation step at $95^{\circ} \mathrm{C}$ for 15 minutes; followed by 40 cycles of denaturation at $95^{\circ} \mathrm{C}$ for 25 seconds, annealing, and elongation steps at $59^{\circ} \mathrm{C}$ for 1 minute; and a final elongation step at $72^{\circ} \mathrm{C}$ for 3 minutes. To evaluate differences in gene expression, we chose a relative quantification method in which the expression of target gene is standardized by one or two nonregulated reference genes (ie, GADPH or GNB2L1). The mathematical method presented by Pfaffl, ${ }^{31}$ which calculates the efficiency of each PCR using a standard curve, was applied. To calculate the relative expression ratio, we used the $\Delta \Delta \mathrm{C}_{\mathrm{T}}$ method implemented in the software of the Applied Biosystems thermal cycler. ${ }^{32}$

\section{Gene Expression Experiments}

Control RNA pool and RNA samples obtained from three different silencing experiments were linearly amplified with the MessageAmp amplified RNA (aRNA) amplification kit (Ambion, Austin, TX), labeled with Cy3 and Cy5 dye (Amersham Biosciences, Chandler, AZ) and competitively hybridized to oligonucleotide microarray platforms (GeneExpression Omnibus ID: GPL2136). For each sample, we performed at least two microarray experiments. Array fluorescence was quantified with ScanArray Express software
(PerkinElmer Inc, Wellesley, MA), and data were normalized with MIDAS tool. ${ }^{33}$ All experiments were analyzed by the SAM program, ${ }^{34}$ implemented in tMEV software. ${ }^{35}$ The list of differentially expressed genes was functionally classified using Gene Ontology (GO) criteria, as implemented in DAVID. ${ }^{36}$ The data discussed in this publication have been deposited in the National Center for Biotechnology Information's GeneExpression Omnibus ${ }^{37}$ database (http:// www.ncbi.n/m.nih.gov/geo, last accessed July 27, 2010) and are accessible through accession number GSE23196.

\section{Western Blot Analysis}

Cells cultured under desired conditions were lysed in buffer $(50 \mathrm{mmol} / \mathrm{L}$ Tris- $\mathrm{HCl}, \mathrm{pH}$ 7.5; $150 \mathrm{mmol} / \mathrm{L}$ sodium chloride; $2 \mathrm{mmol} / \mathrm{L}$ EDTA; $1 \%$ Triton; $0.5 \%$ sodium deoxycholate; and $0.1 \%$ SDS) containing protease inhibitors (Sigma-Aldrich, St Louis, MO). Lysates were incubated on ice and centrifuged for 30 minutes at $13,000 \times g$, and supernatants were removed and stored at $20^{\circ} \mathrm{C}$ until use. Conditioned medium for analysis of secreted proteins was concentrated using a Centricon filter (Millipore, Billerica, MA). Equal amounts of secreted or whole-lysate proteins (30 $\mu \mathrm{g}$ of protein per lane) were separated by $4 \%$ to $12 \%$ SDS-PAGE (Invitrogen Life Technologies) and transferred to nitrocellulose membranes (Amersham Biosciences). Membranes were blocked for 1 hour at room temperature with $3 \%$ nonfat milk in PBS and then incubated with diluted goat polyclonal anti-IGFBP2 (1:1000, C-18; Santa Cruz Biotechnology, Santa Cruz, CA) or with anti- $\beta$-actin (1:3000; Sigma-Aldrich) in PBS containing $0.1 \%(\mathrm{v} / \mathrm{V})$ Tween 20 overnight at $4^{\circ} \mathrm{C}$. After washing three times for 5 minutes each with PBS containing $0.1 \%(\mathrm{v} / \mathrm{v})$ Tween 20 at room temperature, membranes were incubated at room temperature for 1 hour with a diluted peroxidase-labeled secondary antibody. The membranes were then washed three times for 5 minutes with PBS containing $0.1 \%(\mathrm{v} / \mathrm{v})$ Tween 20 at room temperature, and immunopositive signals were visualized using an enhanced chemiluminescence detection kit (Cyanagen, Bologna, Italy). The protein levels were quantified using Quantity One software (ChemiDoc-Bio-Rad, Hercules, CA). The control sample was set to one, and all RMS cell results were related to this value. $\beta$-Actin was used as an internal reference for data normalization.

\section{Immunofluorescence Assays}

Cells cultured on glass coverslips in six-well dishes were washed in PBS, fixed with $4 \%$ paraformaldehyde, and permeabilized in $50 \mathrm{mmol} / \mathrm{L} \mathrm{NH} \mathrm{Nl}_{4} \mathrm{Cl}$ and $0.2 \%$ Triton X-100 in PBS. After fixation, the cells were blocked with $1 \%$ bovine serum albumin in PBS for 30 minutes at room temperature. Cells were incubated with primary antibodies (IGFBP2, 1:50, and GM130, 1:500; BD Biosciences, San Jose, $C A$ ), diluted in $1 \%$ bovine serum albumin in PBS for 1 hour in a humidified incubator at $37^{\circ} \mathrm{C}$. After washing with PBS, cells were incubated for 30 minutes in a dark chamber with the corresponding secondary goat fluorochrome-conjugated antibodies. Alexa Fluor 488 (green) or 568 (red) secondary antibodies were obtained 
from Invitrogen (Life Technologies). Subsequently, the slides were washed three times with PBS, and cell nuclei were counterstained with DAPI mounted with gel Mount Aqueous Mounting medium (Sigma-Aldrich) and examined using an $\times 40$ or $\times 63$ objective of a Leica $5000 \mathrm{~B}$ microscope (Leica Microsystems, Newcastle upon Tyne, UK). Controls with no or only one primary antibody or both secondary antibodies alone or in combination were used to exclude nonspecific background staining. In case of treatment with brefeldin A (BFA) before fixation for staining, the culture medium was replaced with serum-free medium containing BFA (Sigma-Aldrich) to a final concentration of $10 \mu \mathrm{g} / \mathrm{mL}$, and the cells were cultured for 1 hour.

\section{Aequorin Measurements}

All measurements were performed as previously described. ${ }^{38}$ Briefly, for reconstituting with high efficiency the aequorin chimera targeted to the Golgi apparatus (GoAEQ), the luminal $\mathrm{Ca}^{2+}$ concentration of this compartment must be reduced first. This was achieved by incubating cells for 1 hour at $4^{\circ} \mathrm{C}$ in Krebs-Ringer buffer (125 mmol/L NaCl, $5 \mathrm{mmol} / \mathrm{L} \mathrm{KCl}, 1 \mathrm{mmol} / \mathrm{L} \mathrm{Na} \mathrm{PO}_{4}, 1$ mmol/L MgSO, $5.5 \mathrm{mmol} / \mathrm{L}$ glucose, $20 \mathrm{mmol} / \mathrm{L}$ HEPES, $\mathrm{pH} 7.4$, at $37^{\circ} \mathrm{C}$ ) supplemented with $5 \mu \mathrm{mol} / \mathrm{L}$ coelenterazine, $5 \mu \mathrm{mol} / \mathrm{L} \mathrm{Ca}^{2+}$ ionophore ionomycin, and 600 $\mu \mathrm{mol} / \mathrm{L}$ EGTA. After this incubation, cells were extensively washed with Krebs-Ringer buffer supplemented with $2 \%$ bovine serum albumin and then a 13-mm round coverslip with the transfected cells was placed in a perfused thermostatic chamber placed in close proximity to a lownoise photomultiplier, with a built-in amplifier-discriminator. The output of the discriminator was captured by a Thorn-EMI photon counting board (Torn-EMI Ltd, Hayes, Middlesex, UK) and stored in a computer for further analyses. When the EGTA of the perfusion buffer was replaced with $1 \mathrm{mmol} / \mathrm{L} \mathrm{CaCl}_{2}, \mathrm{Ca}^{2+}$ concentration Golgi rapidly increased. Then, the addition of ATP, an agonist coupled to inositol 1,4,5-trisphosphate production, caused a rapid and extensive decrease in the Golgi $\mathrm{Ca}^{2+}$ concentration.

The aequorin luminescence data were calibrated offline into $\mathrm{Ca}^{2+}$ concentration values, using a computer algorithm based on the $\mathrm{Ca}^{2+}$ response curve of wild-type and mutant aequorins, as previously described. ${ }^{39}$

\section{VSVG Imaging}

C2C12, RH30, and RH36 cells were seeded on 25-mm coverslips previously coated with $0.01 \%$ poly-D-lysine (for 1 hour at $37^{\circ} \mathrm{C}$ ). At 48 hours after plating, cells were transfected with the temperature-sensitive variant of the G protein of vesicular stomatitis virus (VSVG), tagged with green fluorescent protein (GFP; provided from Dr. Jennifer Lippincott-Schwartz, NIH, Bethesda, MD) using Lipofectamine 2000 (Invitrogen Life Technologies). In detail, a Lipofectamine-DNA mix was prepared in Optimem (Invitrogen Life Technologies) with a ratio of $8 \mu \mathrm{L} / 1 \mu \mathrm{g}$. After 30 minutes, the mixture was placed on cells growing in Dulbecco's modified Eagle's medium plus 10\% fetal bovine serum. At 48 hours after transfection, the cells were shifted to $15^{\circ} \mathrm{C}$ for 3 hours to accumulate cargoes in the intermediate compartments. Then, cargoes were released to proceed into the Golgi complex by shifting the temperature back to $37^{\circ} \mathrm{C}$. Cells were then imaged with Nikon Swept Field Confocal equipped with CFI Plan Apo VC60XH objective (numerical aperture, 1.4) (Nikon Instruments, Melville, NY) and an Andor DU885 electron multiplying charge-coupled device (EM-CCD) camera (Andor Technology Ltd, Belfast, Northern Ireland). Coverslips were placed in an incubated chamber with a controlled temperature, $\mathrm{CO}_{2}$, and humidity; then, z-stacks were acquired by 21 planes with a 0.6- $\mu \mathrm{m}$ distance, to allow acquisition of the whole cell. Intensity measurements and three-dimensional rendering were obtained by using open source software Fiji (http://fiji.sc/ wiki/index.php/Fiji, last accessed June 20, 2011). In detail, membrane regions were obtained by generating a threshold-based mask of the whole cell; then, with the edge detection and dilated functions, a region for measuring the membrane signal was obtained. A higher threshold was used to detect Golgi aggregates (because of the distribution of the signal) and vesicles with VSVGGFP localization. Golgi aggregates were then filtered from vesicles using the analyzed particle function; objects $<100$ pixels $^{2}$ were excluded.

\section{Electron Microscopy}

C2C12 and RMS cells were grown to $70 \%$ confluence. After washing with PBS, cells were fixed with $4 \%$ paraformaldehyde in PBS for 1 hour, embedded in $12 \%$ gelatin, infiltrated with $2.3 \mathrm{~mol} / \mathrm{L}$ sucrose, and then frozen in liquid nitrogen. Ultrathin cryosections were obtained with Leica Ultracut UCT microtome, with a Leica EM FCS cryoattachment and collected on copper-formavar carbon-coated grids (Leica Microsystems). Double-immunogold labeling was performed as previously described. ${ }^{40}$ Briefly, the sections were incubated with goat antiIGFBP2 antibody. Rabbit anti-goat 10-nm gold-conjugated protein A was used to reveal the primary antibody staining. Then, sections were incubated with rabbit antigiantin, followed by $15-\mathrm{nm}$ gold-conjugated protein $\mathrm{A}$ as the secondary antibody. The samples were examined using an FEI CM10 and Tecnai G12 electron microscope (FEl company, Eindhoven, The Netherlands).

\section{Flow Cytometric Analysis of the Cell Cycle}

After transfection, IGFBP2-silenced (silGFBP2) and control (siCONTROL) cells were harvested. For each sample, $1 \times 10^{6}$ cells were fixed with $70 \%$ cold ethanol, washed with PBS, and incubated with propidium iodide $(50 \mu \mathrm{g} /$ $\mathrm{mL})$ and RNase $(100 \mu \mathrm{g} / \mathrm{mL})$ for 60 minutes at $37^{\circ} \mathrm{C}$. Samples were run in a BD FACScan (Becton Dickinson, Labware, Bedford, MA), and data were analyzed with ModFitLT V3.0 software (Verity Software House, Topsham, ME). Two independent samples were analyzed for each cell type. 


\section{Migration and Invasion Transwell Assay}

Migration was tested using cell culture inserts (Transwell) with an 8- $\mu \mathrm{m}$ pore size membrane (24-well format; Becton Dickinson). Chemoinvasion was measured using 24well BioCoat Matrigel invasion chambers (Becton Dickinson) with an 8- $\mu \mathrm{m}$ pore polycarbonate filter coated with Matrigel. The lower compartment contained $0.5 \mathrm{~mL}$ of $1 \%$ serum medium conditioned by the NIH3T3 cell line as a chemoattractant or serum-free Dulbecco's modified Eagle's medium as a control. In the upper compartment, $10^{5}$ $\mathrm{RH} 36$ cells per well were placed in triplicate wells and incubated for 18 hours at $37^{\circ} \mathrm{C}$ in a humidified incubator with a $5 \% \mathrm{CO}_{2}$ atmosphere. After incubation, the cells on the upper surface of the filter were wiped off with a cotton swab, whereas the cells on the lower surface were fixed in $2.5 \%$ glutaraldehyde, stained with $0.2 \%$ crystal violet in $20 \%$ methanol, and then photographed using a stereomicroscope (model MZ16; Leica Microsystems) equipped with a CCD camera. Images were elaborated with CorelDraw software (Corel, Ottawa, Canada), and the area occupied by the migrated cells was measured by using ImageJ software (http://rsbweb.nih.gov/ij, last accessed September 4, 2009).

\section{Lentiviral Infections and Gene Silencing with shRNAs}

The lentiviral expression vectors were obtained from Sigma-Aldrich, and cells were infected as previously described. ${ }^{41}$

\section{Seeding Assay}

All animal experiments were conducted in compliance with national legislation on ethical animal care. Female CD1 nude mice, aged 7 weeks (Charles River Laboratories, Wilmington, $M A$ ), were injected in the tail vein with $1.6 \times 10^{6} \mathrm{RH} 36$ IGFBP2-silenced or control $\mathrm{RH} 36$ cells, previously labeled with CellTracker Orange CMRA (Molecular Probes, Invitrogen Life Technologies), and resuspended in PBS. After 48 hours, mice were sacrificed and $4 \%$ paraformaldehyde was injected into the trachea. Lungs were dissected and photographed using a Leica MZ16F fluorescence stereomicroscope (Leica Microsystems), and the mean of the total red fluorescent (CMRA) tumor cells present in three representative pictures per lungs per animal was evaluated using ImageJ software. Twelve mice per group were used.

\section{IHC Analysis}

Sections (4- $\mu \mathrm{m}$ thick) from paraffin-embedded tissues were dewaxed in xylene, rinsed in graded ethanol, and rehydrated in distilled water. For antigen retrieval, slides were pretreated by steaming in EDTA citrate buffer $(\mathrm{pH}$ 9.0) for 15 minutes at $100^{\circ} \mathrm{C}$. Then, the sections were treated with $3 \% \mathrm{H}_{2} \mathrm{O}_{2}$ for 5 minutes at room temperature to block endogenous peroxidase activity. After washing with PBS, the sections were manually immunostained with anti-IGFBP2 antibody at 1:100 dilution. For mouse monoclonal anti-58k antibody (GeneTex, Irvine, CA), the $\mathrm{IHC}$ stain was performed using a Bond MaX automated immunostainer (Leica Microsystems). The 58k primary antibody was used at 1:1000 dilution for 15 minutes. IGFBP2 was detected using the ABC Elite method (Vector Laboratories, Burlingame, CA), whereas mouse monoclonal anti-58K was detected using the polymer Refine detection kit (Leica Microsystems), according to the manufacturer's instructions. Hematoxylin was used for counterstaining. Specimens were then dehydrated with alcohol. The sections were analyzed with a Leica DM4000B-M microscope at either $\times 20$ or $\times 40$ amplification (Leica Microsystems). A human placenta tissue section was used as the positive control.

\section{ELISA Assays}

IGFBP2 plasma levels were determined by using the IGFBP2 enzyme-linked immunosorbent assay (ELISA) kit (RayBiotech, Inc., Norcross, GA), according to the manufacturer's instructions. Each assay was repeated three times, and the mean concentration of IGFBP2 was used for further statistical analysis.

\section{Statistical Analysis \\ Microarray}

All microarray experiments were analyzed by the SAM program implemented in tMEV software. SAM uses a permutation-based multiple testing algorithm and identifies significant genes with variable false-discovery rates. The list of differentially expressed genes presenting a false-discovery rate of 0 was classified in terms of biological functions using DAVID, a functional annotation tool. This type of analysis was aimed at identifying functional categories from the $\mathrm{GO}$ and public gene annotation databases that are present in the IGFBP2-silenced expression signature more frequently than expected by chance alone. The Group Enrichment Score is used to rank their biological significance. Thus, the top ranked annotation groups most likely have consistent lower $P$ values for their annotation members.

\section{Seeding}

Data are calculated as mean \pm SEM number of seeded cells 48 hours after injections for 12 mice per group, and the two-tailed Student's $t$-test was used for comparisons, with $P<0.05$ considered a statistically significant value.

\section{ELISA Data}

Two or three independent experiments were performed in triplicate for each sample. Significance was evaluated using the Student's t-test or an F test that does not assume equal variances, and $P<0.05$ was considered statistically significant. We performed the nonparametric U-test and the Wilcoxon signed rank test. An analysis of variance multiway analysis was used to correlate 

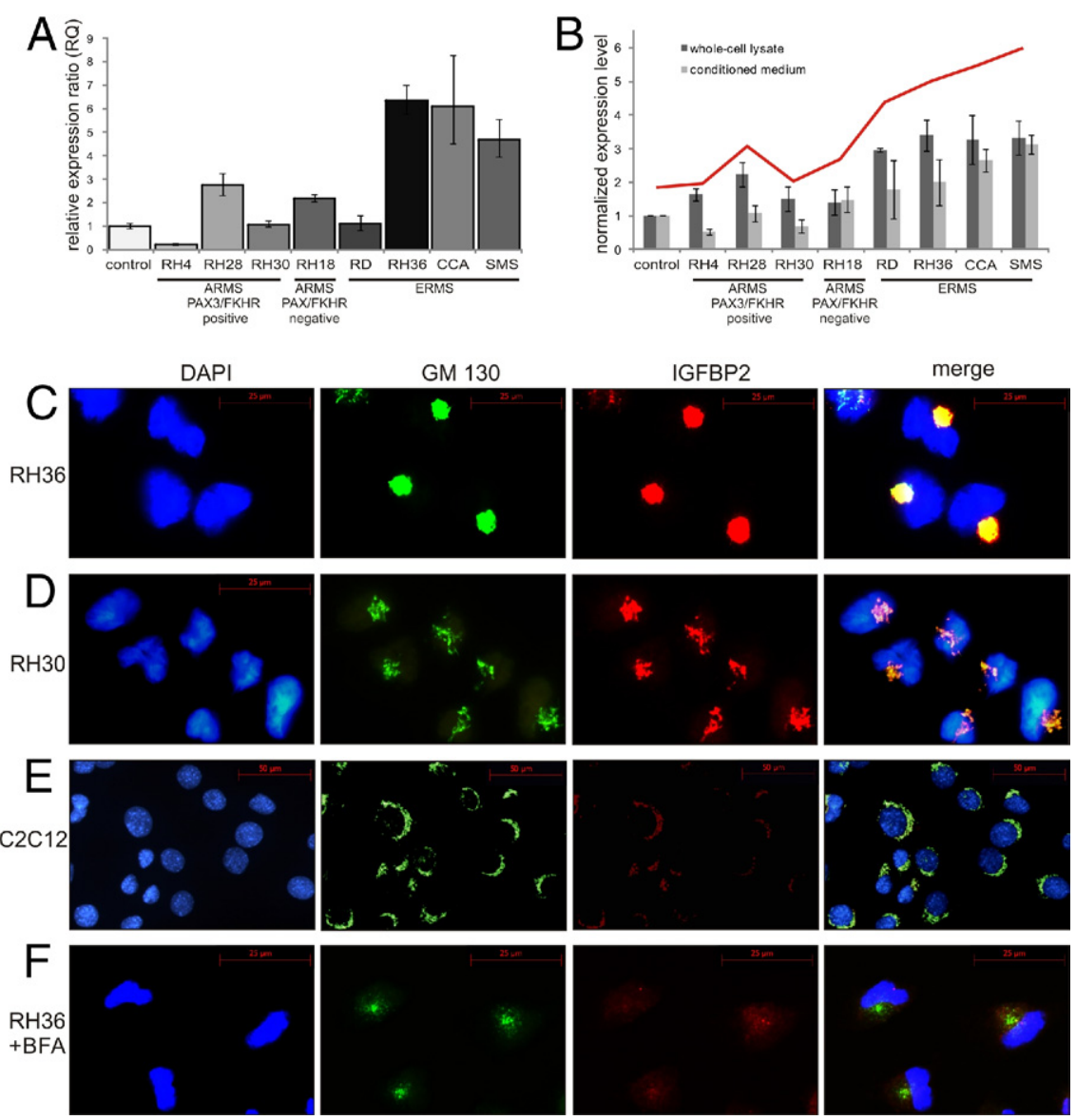

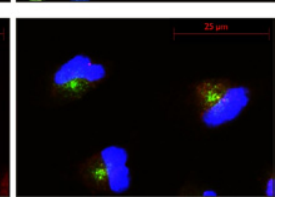

Figure 1. IGFBP2 accumulates in the Golgi of RMS cell lines. A: RT-qPCR evaluation of IGFBP2 expression in different RMS cell lines classified as indicated. Results are shown as relative expression ratio obtained with the $\Delta \Delta \mathrm{C}_{\mathrm{T}}$ method. $G A D H$ and G2BNL1 were used as reference genes. Vertical bars indicate $95 \%$ confidence interval. B: IGFBP2 protein content was measured in whole-cell lysate (dark gray bars) and in medium (light gray bars) of the same RMS cell lines as in $\mathbf{A}$ by using Western blot analysis. Quantity One software was used for quantitation. Values are calculated as fold changes relative to $\mathrm{C} 2 \mathrm{C} 12$ control cells and normalized to $\beta$-actin level. Vertical bars indicate $95 \%$ confidence interval. The trend line (red) was calculated by adding the lysate and medium protein values. C-F: Immunostaining of ERMS cell line RH36 (C), PAX3/ FKHR-positive ARMS cell line $\mathrm{RH} 30$ (D), and control cell line C2C12 (E) with DAPI for nuclei (blue), anti-GM130 antibody for Golgi (green), and anti-IGFBP2 antibody (red). The pictures of the last column are obtained by merging the GM130 and IGFBP2 antibody signals. F: Immunostaining of RH36 cells after BFA treatment shows the simultaneous releasing of GM130 antigen and IGFBP2 from Golgi into the cytoplasm The image is restricted to few cells to highlight the distribution of Golgi marker protein, but all of the cells show the same staining pattern. the IGFBP2 level with other clinical parameters, and $P<$ 0.05 was considered statistically significant.

\section{Results}

\section{Analysis of IGFBP2 in RMS Cell Lines}

The presence or absence of the PAXIFKHR fusion gene identifies two different gene expression signatures in RMS. ${ }^{28,29}$ Because IGFBP2 emerged as one of highly overexpressed genes in PAXIFKHR-negative RMS, we hypothesized that it may play a role in growth and differentiation of this tumor. To test this, we first studied the expression of IGFBP2 in eight RMS cell lines and in the myoblast $\mathrm{C} 2 \mathrm{C} 12$ cell line as a control. We found that IGFBP2 expression in cell lines mirrors the expression pattern of the histologically related RMS samples analyzed in our previous microarray study. ${ }^{29}$ In fact, IGFBP2 mRNA (Figure 1A) and both the intracellular and secreted protein fractions (Figure 1B) were significantly more abundant in most PAXIFKHR fusion-negative cell lines. The higher concentration of secreted IGFBP2 in culture medium of fusionnegative cells was also confirmed by ELISA (see Supplemental Figure S1 at http://ajp.amjpathol.org).

An analysis of the intracellular localization of IGFBP2 revealed that the protein was concentrated in a perinuclear region of RMS cells (Figure 1C). IGFBP2 was more abundant in the embryonal $\mathrm{RH} 36$ cell line compared with the alveolar PAX3/FKHR-positive RH30 cell line (Figure 1D). The differential expression of IGFBP2 between ARMS and ERMS was confirmed in other RMS cell lines (data not shown). In the cytoplasm of the control cell line C2C12, the IGFBP2 signal was low (Figure 1E). Co-immunostaining with an antibody directed against the cisGolgi matrix protein GM130 demonstrated the concentration of IGFBP2 in the Golgi apparatus. This finding was confirmed by treatment of RMS cells with BFA, a fungal metabolite that inhibits protein secretion in eukaryotic cells by interfering with the function of the Golgi apparatus. ${ }^{42}$ On BFA treatment, we observed a redistribution of IGFBP2 in the cytoplasm of RMS cells (Figure 1F). Interestingly, IGFBP2-expressing RMS cells showed an unusual modification of the Golgi morphological features that appeared condensed in a juxtanuclear position and without their typical stack organization. This peculiar organization appears to depend on the level of accumulated protein, as shown in the different cell lines analyzed (Figure 1, C and D).

\section{RMS Cells Show Morphological and Functional Alterations of Golgi Apparatus}

We analyzed whether the conspicuous morphological changes in the Golgi apparatus complex, seen in RMS cells by immunofluorescence experiments, were accompanied by functional alterations of this organelle. The 


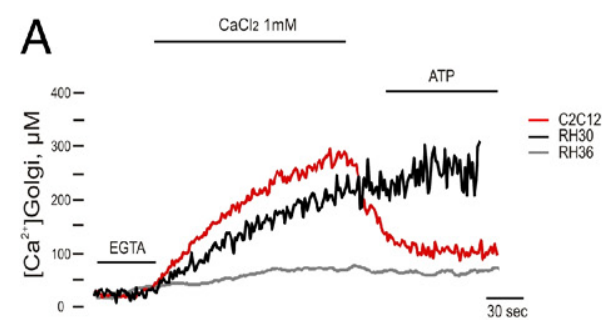

$\mathrm{B}$

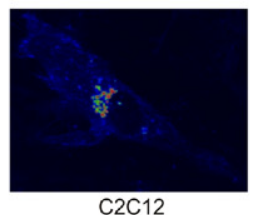

$\mathrm{C} 2 \mathrm{C} 12$

$\mathrm{E}$
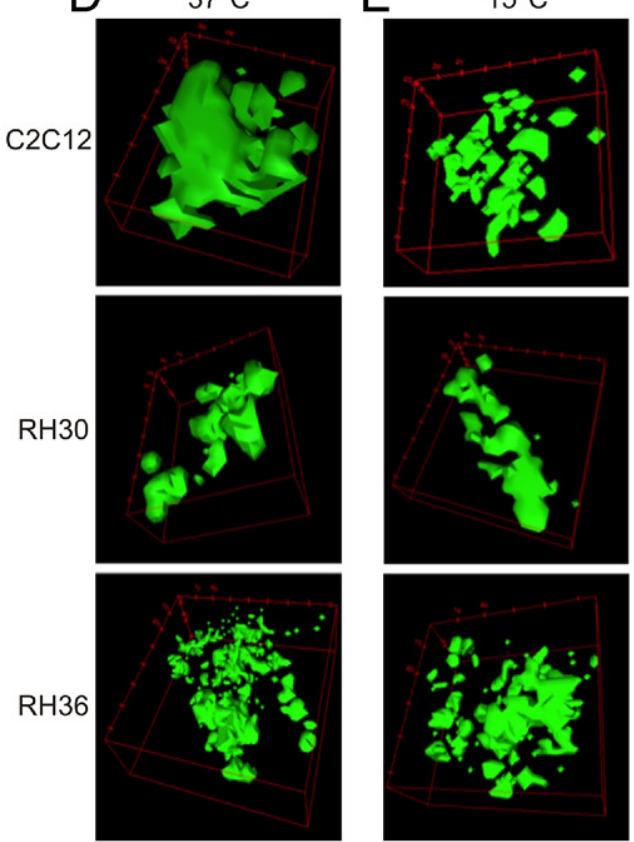
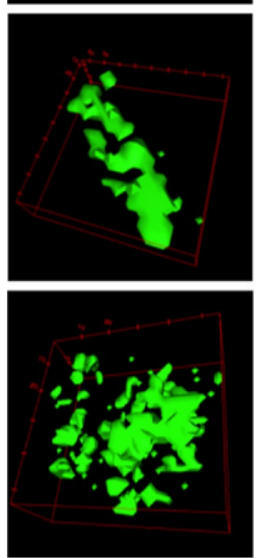

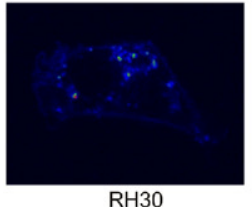

$\mathrm{F}$
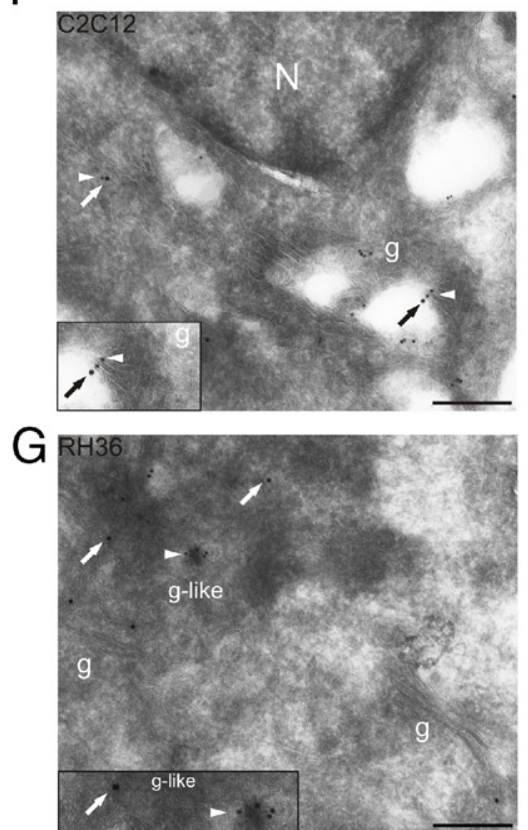

Figure 2. Morphological and functional alterations of Golgi apparatus in RMS cells. A: Golgi $\mathrm{Ca}^{2+}$ homeostasis measurements with aequorins in C2C12 and RMS cells. Where indicated, cells were treated with $\mathrm{CaCl}_{2}$ to assess the filling of the Golgi compartments and with ATP, as agonist, to analyze the release of $\mathrm{Ca}^{2+}$ from the organelle. RMS cells showed a deregulation of Golgi $\mathrm{Ca}^{2+}$ homeostasis, in particular RH36 (gray line), in which the Golgi apparatus apparently failed to both accumulate and release $\mathrm{Ca}^{2+}$ after agonist stimulation. B: Analysis of VSVG-GFP distribution in C2C12 and RMS cell lines at $37^{\circ} \mathrm{C}$. C: Percentage of VSVG-GFP intensity at plasma membrane compared with overall signal. A significant $\left({ }^{*} P<0.05\right)$ increase in VSVG-GFP at the cell surface of RMS cells was observed compared with control cells. Vertical bars represent the confidence interval of single-cell signals of three independent experiments. D and E: VSVG-GFP signal from the Golgi compartment at $37^{\circ} \mathrm{C}(\mathbf{D})$ and at $15^{\circ} \mathrm{C}(\mathbf{E})$ revealed a more fragmented Golgi apparatus with clear morphological changes in RMS cells compared with C2C12 cells. F and G: Ultrathin cryosections of C2C12 (F) and RMS (G) cells were double labeled with antibodies against giantin (15-nm gold, arrows), a Golgi marker, and IGFBP2 (10-nm gold, arrowhead). IGFBP2 colocalizes in giantin-labeled enlarged vesicles at the edge of Golgi cisterns in RH36 cells. Scale bars: 192 nm (F and G). g, Golgi; N, nuclei.

Golgi apparatus acts as $\mathrm{Ca}^{2+}$ store, and changes in calcium concentration within the Golgi lumen regulate Golgi function, controlling some of the key processes of cell biology, such as protein trafficking and sorting. ${ }^{38}$ Therefore, we assayed the dynamic variations of $\mathrm{Ca}^{2+}$ concentration homeostasis within the Golgi apparatus using the recombinant $\mathrm{Ca}^{2+}$-sensitive bioluminescent protein aequorin, modified with a specific tag for localization in this organelle (Golgi aequorin protein [GoAEQ]). ${ }^{38}$ To obtain reliable quantitative estimates of $\mathrm{Ca}^{2+}$ concentration in the lumen of the Golgi apparatus, its $\mathrm{Ca}^{2+}$ concentration needs to be decreased during both the reconstitution of aequorin with coelenterazine and the subsequent initial phase of perfusion with KrebsRinger buffer-EGTA in the luminometer (see Materials and Methods). After $\mathrm{Ca}^{2+}$ depletion of the organelle, we investigated the characteristics of the $\mathrm{Ca}^{2+}$ uptake and release after agonist stimulation. When the EGTA in the perfusion buffer was replaced with $1 \mathrm{mmol} / \mathrm{L} \mathrm{CaCl}$, Golgi $\mathrm{Ca}^{2+}$ rapidly increased up to a concentration of approx- imately $300 \mu \mathrm{mol} / \mathrm{L}$ (Figure 2A) in C2C12 cells. Production of inositol 1,4,5-trisphosphate activates channels on the Golgi membrane, resulting in $\mathrm{Ca}^{2+}$ release from the apparatus. Indeed, when C2C12 cells were stimulated with ATP (an agonist of inositol 1,4,5-trisphosphate production), a release of $\mathrm{Ca}^{2+}$ from the Golgi membrane was observed (Figure 2A). On the contrary, a deregulation of Golgi $\mathrm{Ca}^{2+}$ homeostasis was detected in two different RMS cell lines. The Golgi apparatus of $\mathrm{RH} 30$ cells showed a normal $\mathrm{Ca}^{2+}$ uptake, reaching the same steady state observed in C2C12 but a completely compromised $\mathrm{Ca}^{2+}$ release after ATP treatment (Figure 2A). The alteration is more evident in $\mathrm{RH} 36$ cells, in which the Golgi apparatus apparently failed to both accumulate and, in turn, release $\mathrm{Ca}^{2+}$ after agonist stimulation (Figure 2A). These data suggest that RMS cells have a defective $\mathrm{Ca}^{2+}$ homeostasis in the Golgi apparatus.

To investigate whether the deregulation of $\mathrm{Ca}^{2+}$ can affect protein sorting and trafficking from Golgi to the plasma membrane, we used the viral glycoprotein VSVG, 
tagged with GFP (VSVG-GFP). ${ }^{43}$ Protein transport analysis in control $\mathrm{C} 2 \mathrm{C} 12$ cells showed that, at $37^{\circ} \mathrm{C}$, VSVGGFP moves from the Golgi to the plasma membrane (Figure 2B). An analysis of VSVG-GFP protein distribution in RMS cells at $37^{\circ} \mathrm{C}$ revealed significant accumulation of protein at the cell surface compared with control cells $(P<0.05$, Figure $2 \mathrm{C})$. These data suggest an active production of secreted proteins in RMS cells, probably linked to the deregulation of protein transport. A colocalization experiment, using GM130 as a specific Golgi marker, confirmed that VSVG-GFP transits through Golgi in control and RMS cells during its secretory process (see Supplemental Figure S2 at http://ajp.amjpathol.org). Therefore, by focusing on the VSVG-GFP signal from the Golgi compartment, in C2C12 cells, we observed normal morphological features of the Golgi apparatus that appeared with its stacking organization (Figure 2D). In contrast, in RMS cells, the distribution of VSVG-GFP protein revealed a more fragmented Golgi, with clear morphological changes (see Supplemental Videos S1, S2, and S3 at http://ajp.amjpathol.org).

The use of a mutant gene encoding a temperaturesensitive VSVG-GFP allowed us to localize the protein in different cellular compartments. At temperatures as low as $15^{\circ} \mathrm{C}$, mutant VSVG-GFP accumulates in intermediate structures called pre-Golgi apparatus that appeared markedly enlarged and accumulate secretory products. ${ }^{44}$ Indeed, at $15^{\circ} \mathrm{C}$, we observed an altered distribution of VSVG-GFP in C2C12 cells with accumulation of the protein in Golgi structures that appear more fragmented, similar to RMS cells (Figure 2E). However, VSVG-GFP protein localization in $\mathrm{RH} 30$ and $\mathrm{RH} 36$ cells was not affected by temperature, indicating that, in these cells, there is a continuous accumulation of secretory products in an altered Golgi compartment.

This hypothesis was confirmed by electron microscopy analysis. Cryosections of $\mathrm{C} 2 \mathrm{C} 12$ control cells and IGFBP2-overexpressing $\mathrm{RH} 36$ cells were immunolabeled with specific antibodies against IGFBP2 and giantin, a Golgi apparatus marker. In C2C12 cells, the distribution of IGFBP2 in the Golgi apparatus was as expected for a typical secreted protein (Figure 2F). In ERMS cell RH36, some normal Golgi apparatus stacks were found, but the IGFBP2 pattern was peculiar because the protein accumulated at the edge of membrane-bound cisterns, reactive with Golgi-specific marker, that appeared less defined than normal Golgi apparatus cisterns (Figure 2G). Taken together, these data suggest that, in RMS cells, the morphological alterations are likely involving only a selected portion of the Golgi apparatus that appears to be made up of structures resembling altered and enlarged vesicles, possibly because of abnormal accumulation of secreted proteins.

\section{Gene Expression Modification in RMS Cells after Silencing IGFBP2}

We used siRNA to examine the effects of IGFBP2 suppression in the IGFBP2-overexpressing ERMS cell line $\mathrm{RH} 36$. As a result, IGFBP2 abundance was dramatically reduced at both the mRNA and protein levels after 48 hours of siRNA treatment (Figure 3, A and B). Moreover, a low level of IGFBP2 protein positively correlated with a change of Golgi shape that appears less condensed, probably because of a decrease of secretory vesicles (Figure 3C).

To identify the networks of genes whose expression was influenced by and functionally related to IGFBP2 reduction, we obtained the profiles of RMS cells from three independent experiments of IGFBP2 silencing and compared them with RMS cells treated with a pool of nontargeted siRNAs, used as controls. A total of 603 genes were differentially expressed in silenced RMS cells, equally distributed between up- and down-regulated genes (see Supplemental Table S3 at http://ajp. amjpathol.org). A functional annotation web tool (DAVID) was used to analyze the biological meaning of the differentially expressed genes. This type of analysis was aimed at identifying functional categories from the GO and public gene annotation databases that are present in the IGFBP2-silenced expression signature more frequently than expected by chance. The Group Enrichment Score was used to rank their biological significance. Thus, the top-ranked annotation groups most likely have consistently lower $P$ values for their annotation members. As a result, we observed that $\mathrm{GO}$ functional categories overrepresented in the up-regulated component of the expression signature included protein transport and Golgi-vesicle transport; in contrast, the down-regulated component showed an overrepresentation of GO categories (ie, regulation of the cell cycle, cell adhesion, and cell motility or migration) (Figure $3, \mathrm{D}$ and $\mathrm{E}$ ). Among the deregulated genes, cyclin D1 (CCND1), MMP2, and minichromosome maintenance protein (MCM) family expression levels were remarkable. Cyclin D1 and the MCMs are implicated in tumorigenesis because of their involvement in the regulation of cell cycle progression. Moreover, correlation of IGFBP2 expression and MMP2 expression was reported. Metalloproteinase proteins act in the modeling of extracellular matrix and are implicated in the acquisition of invasive potential and in tumor progression. Microarray results were validated by RT-qPCR for a sample of 12 genes belonging to different annotation clusters (see Supplemental Figure S3 at http:// ajp.amjpathol.org).

\section{IGFBP2 Silencing Reduces Cell Cycle Progression, Migration, and Invasiveness of RMS Cells in Vitro}

The signatures of IGFBP2-silenced cells showed the involvement of IGFBP2 in cellular pathways generally associated with cancer growth and progression. To validate this observation, cell cycle progression of the IGFBP2silenced cell line (silGFBP2) was compared with control cells (siCONTROL) by flow cytometry. Cells with reduced levels of IGFBP2 showed a decreased proliferation rate and $\mathrm{G}_{0} / \mathrm{G}_{1}$ phase arrest $(P<0.05$, Figure $4 \mathrm{~A})$. Moreover, we tested whether IGFBP2 suppression affected RMS cell migration and invasion in vitro. Both assays revealed 

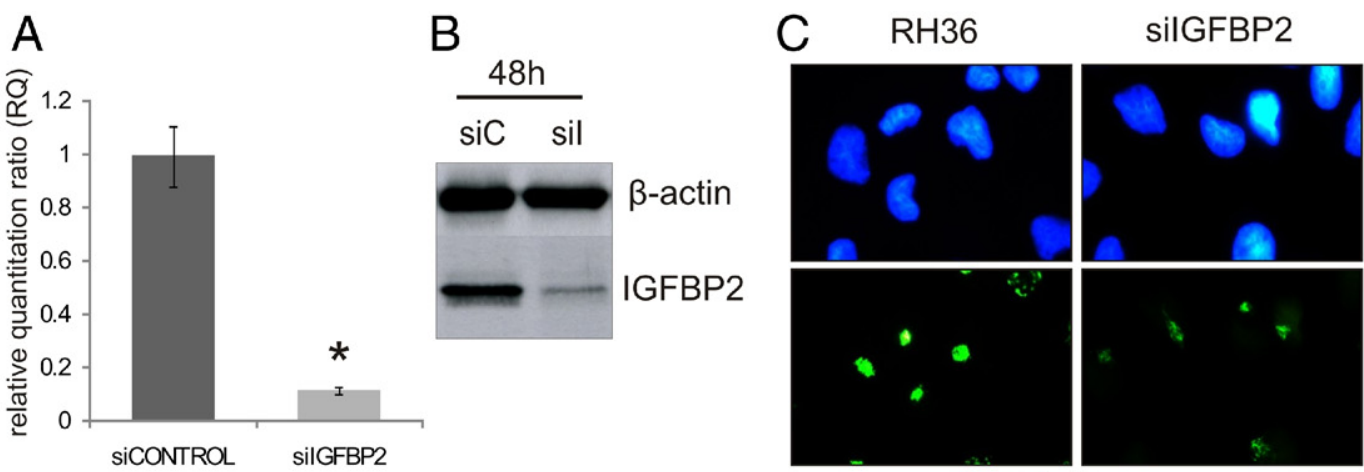

DAPI
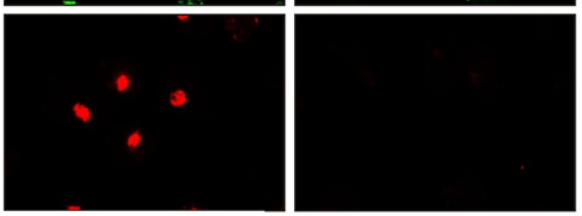

GM130

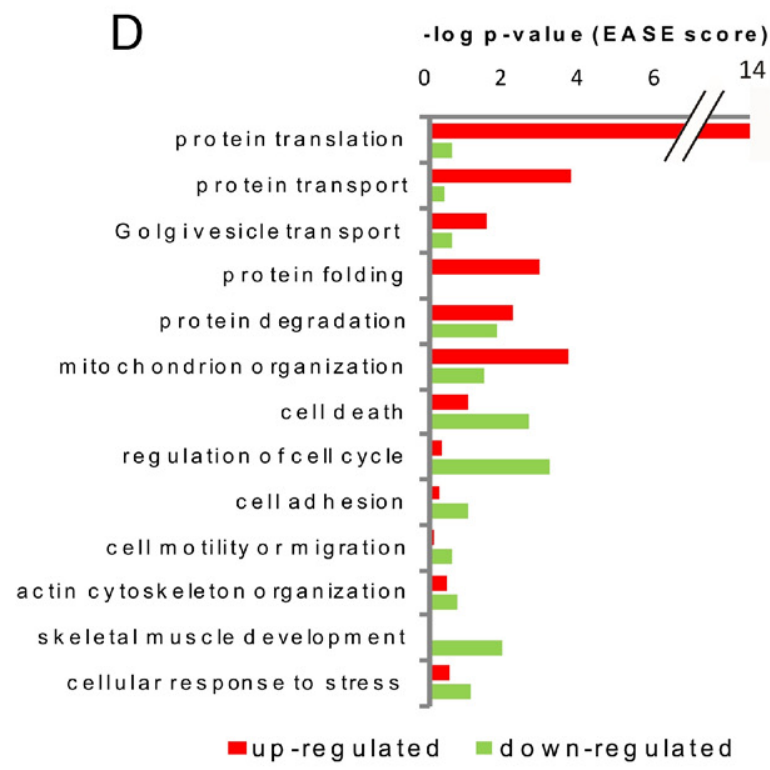

$\mathrm{E}$

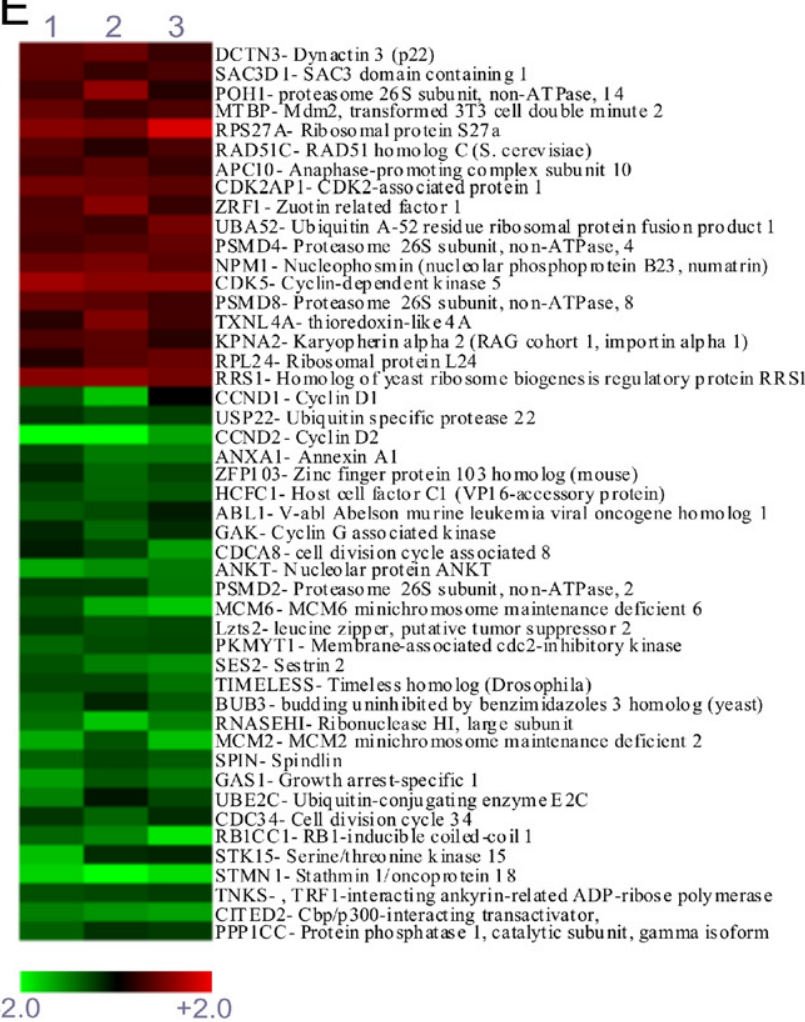

Figure 3. Altered gene pathways in IGFBP2-silenced RMS cells. A: IGFBP2 mRNA level (RQ) measured by RT-qPCR in RH36 cells transfected with the siRNA pool for IGFBP2 (siIGFBP2) or with the nontargeted siRNA pool (siCONTROL). A significant $\left({ }^{*} P<0.05\right)$ decrease of IGFBP2 mRNA level was observed after silencing. B: IGFBP2 protein content measured by immunoblotting of whole cell lysate of RH36 cells treated as in $\mathbf{A}$. Both assays indicate a significant reduction of IGFBP2 mRNA and protein after 48 hours of silencing (siC, siCONTROL; sil, siIGFBP2). C: Immunostaining of RMS cell line RH36 after IGFBP2 silencing (siIGFBP2). Treatment shows that low levels of IGFBP2 correlate with change of Golgi shape that appears less condensed, possibly because of a decrease of secretory vesicles. DAPI for nuclei (blue), anti-GM130 antibody for Golgi (green), and anti-IGFBP2 antibody (red) were used. D: GO functional categories were enriched in up-regulated (red) or down-regulated (green) genes in IGFBP2-silenced RH36 cells. Data were obtained by DAVID and are plotted by the negative log of $P$ value (Group Enrichment Score). E: Heat map representing a selection of deregulated transcripts involved in cell cycle regulation, common to three different IGFBP2-silenced RH36-infected cells. Globally, the microarray data analyzed with the tMEV tool and the SAM algorithm have identified 603 differentially expressed genes. A color-coded scale for the normalized expression values was used, where red represents up-regulation and green represents down-regulation relative to RH36 cells transfected with the siRNA pool (siCONTROL).

a significant reduction of migration and invasion capability of IGFBP2-silenced cells compared with parental cells $(P<0.05$, Figure 4B). Altogether, these results suggest that a high level of IGFBP2 facilitates RMS tumor cell invasion and cell cycle progression in vitro.

\section{IGFBP2 Silencing Reduces Seeding of RMS Cells in Vivo}

To assess whether IGFBP2 influenced tumor progression in vivo, we measured the lung seeding ability of 

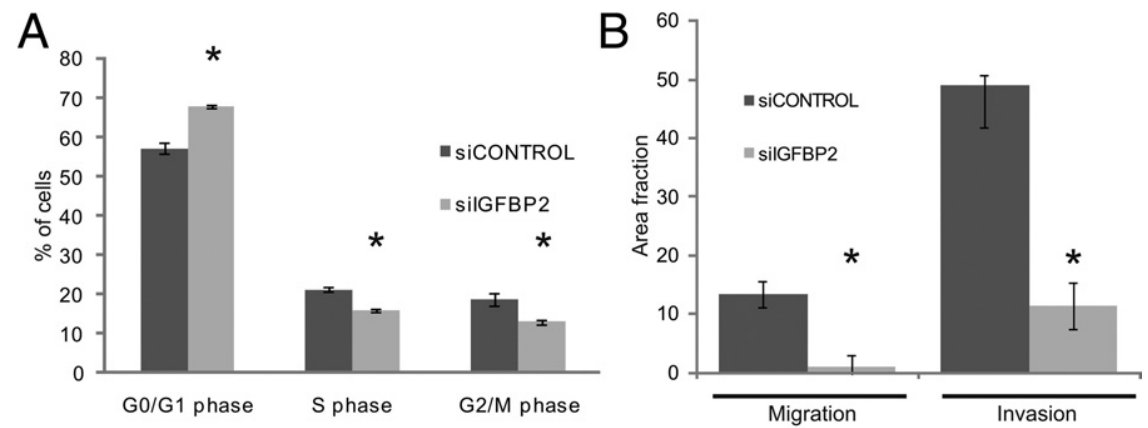

\section{C}

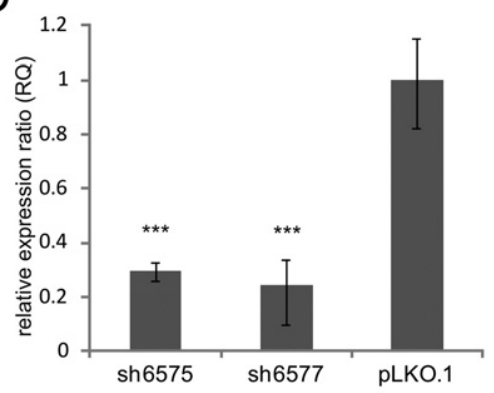

D

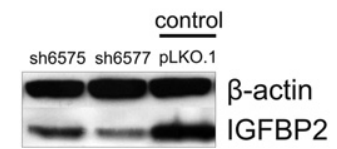

E

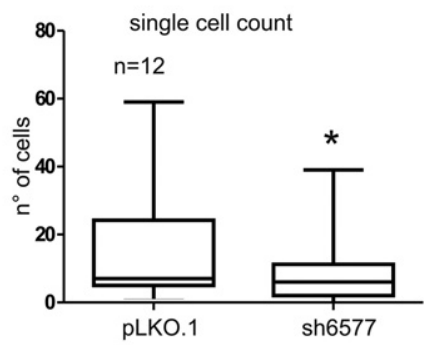

Figure 4. IGFBP2 silencing reduces proliferation cell migration, and invasion of RMS cells in vitro and lung seeding ability in vivo. A: Mean percentages of cells in different cycle phases in RH36 cells silenced with siRNA for IGFBP2 (siIGFBP2, light gray boxes) or with nontargeted siRNA (siCONTROL, dark gray boxes), as measured by flow cytometry. Vertical bars represent the confidence interval among two independent experiments, each performed in triplicate. $\mathrm{A}$ significant $\left({ }^{*} P<0.05\right)$ increase in $G_{0} / G_{1}$ cells is seen in in 1 FP 2-silenced cells, accompanied by a decrease in $S$ and $G_{2} / M$ cells. B: Mean area fractions covered by siIGFBP2 (light gray boxes) and siCONTROLtransfected RH36 cells (dark gray boxes) after Transwell migration (Migration) and Matrigel invasion (Invasion) assays. Vertical bars represent the confidence interval among three independent experiments, each performed in triplicate. Significant $\left({ }^{*} P<0.05\right)$ declines in both parameters are evident after IGFBP2 silencing. C: RT-qPCR measurements of IGFBP2 mRNA (RQ) in RH36 cells stably transduced with lentiviral vectors expressing different IGFBP2-silencing shRNAs (ie, sh6575 and sh6577) or with empty ing shrNAs (ie, s 575 and sh6577) or with empty vector controls (pLKO.1). Expression values are calculated as relative expression ratio obtained with the $\Delta \Delta \mathrm{C}_{\mathrm{T}}$ method. Vertical bars represent the confidence interval of at least three experiments. The data demonstrate a significant ( waw $^{2} P<0.01$ ) stable down-regulation of the IGFBP2-silenced RMS cells. D: IGFBP2 protein content of the same transfected RH36 cells described in $\mathbf{A}$, measured by immunoblotting of whole cell lysate with anti-IGFBP2 antibody. IGFBP2 is reduced in both stably silenced cells. E: In vivo seeding analysis after tail vein injections in nude mice of CMRA-labeled RH36 cells, infected as in $\mathbf{C}$ and $\mathbf{D}$. Data are presented as the mean \pm SEM of the number of cells seeding the lungs, 48 hours after injections for 12 mice per group (see also Materials and Methods). The two-tailed Student's $t$-test was used for statistics. ${ }^{*} P<0.05$.
IGFBP2-silenced RMS and control cells. The RH36 cell line was transduced with five lentiviral vectors containing different IGFBP2 short hairpin RNA (shRNA) sequences. Control cells were transduced with empty pLKO.1 lentiviral vectors or with the same vectors expressing IGFBP2-mutated shRNAs. Specific, strong, and stable IGFBP2 gene silencing was obtained with two shRNA sequences (ie, sh6575 and sh6577), as demonstrated by using RT-qPCR and Western blot assays (Figure 4, C and D). Cells expressing either the sh6575 or the sh6577 sequence showed defects in migration, invasion, and cell cycle compared with control (pLKO.1) cells (see Supplemental Figure S4 at http://ajp.amjpathol.org), as also observed for cells transiently transfected with silGFBP2 (Figure 4B). CMRA-labeled (red) control (pLKO.1) or IGFBP2 sh6577-expressing $\mathrm{RH} 36$ cells were tail vein injected in nude mice, and their ability to seed in the lung parenchyma was evaluated 2 and 48 hours later. Two hours after injection, many cells were still associated with the lung blood vessels, although some cells already crossed the endothelial barrier and were already visible in the lung parenchyma (data not shown). No difference in lodging was observed between IGFBP2 sh6577 and control cells. When cells were counted 48 hours after injection, a reduced seeding ability was observed for IGFBP2 sh6577 cells compared with controls (Figure 4E). These results indicate a positive role for IGFBP2 in early lung colonization events of tumor cells that could depend on intraluminal viability or extravasation or early growth capabilities.

\section{IGFBP2 Expression and Distribution in Patients with RMS Resemble Those of RMS Cell Lines}

The data obtained from both in vitro and in vivo experiments using RMS cell lines indicate IGFPB2 as a protein that plays an important role in RMS tumor progression, proliferation, and invasiveness. Thus, we determined whether these findings could be extended to patients with RMS. Our previous gene expression profiling study, ${ }^{29}$ using patient samples, showed that IGFBP2 is an important discriminating transcript between PAX3/FKHR-positive ARMS and PAX3/ FKHR-negative RMS. To confirm and extend these observations, we tested IGFBP2 mRNA expression in tumor specimens of a novel cohort of patients with RMS using RT-qPCR and demonstrated that PAXIFKHR-positive ARMS expressed significantly less IGFBP2 than PAXIFKHR-negative RMS (Figure 5A).

Subsequently, we assessed the pattern of cellular IGFBP2 distribution in tumor specimens. Thus, we studied paraffin-embedded biopsy specimens of patients with RMS by IHC using anti-IGFBP2 and anti-58k Golgi marker antibodies. Of 13 RMS samples studied (seven ERMS, four PAX3/FKHR positive, and two ARMS negative), all PAXIFHKR-positive ARMS samples showed absent or low IGFBP2 expression (Figure 5B). Six of seven ERMS specimens and all PAXIFHKR fusion-negative ARMSs analyzed were positive for IGFBP2. In the IGFBP2-positive RMSs, we observed a specific staining pattern ranging from diffuse cytoplasmic staining to a more intense signal in the perinuclear region (Figure 5, C 

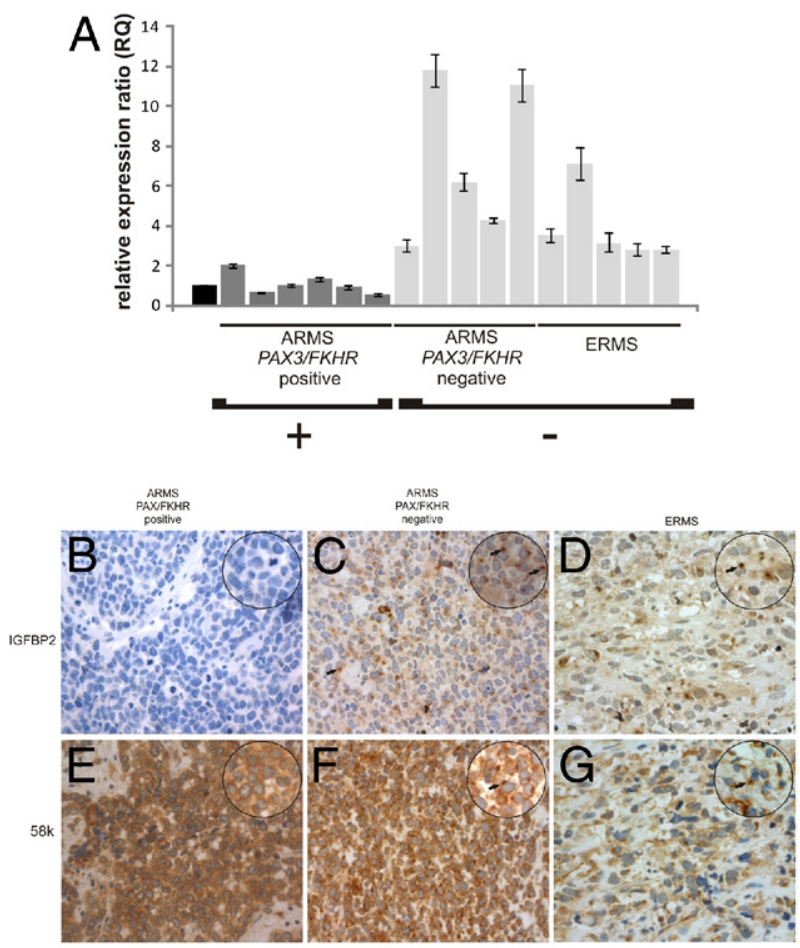

\section{$\mathrm{H}$}
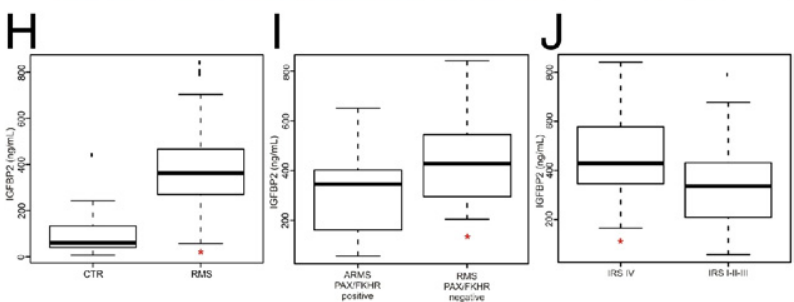

Figure 5. Evaluation of IGFBP2 status in patients with RMS. A: RT-qPCR quantitation of IGFBP2 mRNA in tumor biopsy specimens from 16 patients affected by different subtypes of RMS (ARMS translocation positive and negative and ERMS). Values are calculated as the ratio to the IGFBP2 mRNA content of fetal skeletal muscle (black box) with the $\Delta \Delta \mathrm{C}_{\mathrm{T}}$ method using glyceraldehyde-3-phosphate dehydrogenase (GAPDH) as the reference transcript. Vertical bars are the 95\% confidence interval among at least three measurements. B-G: Immunodetection of IGFBP2 (B-D) and a $58 \mathrm{~K}$ cis-Golgi protein marker $(\mathbf{E}-\mathbf{G})$ in paraffin-embedded sections of tumor samples from the three RMS subtypes described in A. PAX/FKHR positive ARMS shows a negative signal for IGFBP2 (B) and positive staining for $58 \mathrm{~K}$ protein $(\mathbf{E})$. Original magnification, $\times 20$. Instead, $P A X$ / FKHR-negative ARMS shows positive IGFBP2 staining that resembles that of cis-Golgi marker (F). ERMS sections show similar results as $P A X / F K H R-$ negative ARMS for both IGFBP2 (D) and 58K cis-Golgi (F) proteins, even though the number of stained cells appears to be reduced. Original magnification: $\times 40 ; \times 63$ (zoomed images). Arrows, peculiar perinuclear accumulation of IGFBP2 and condensed Golgi apparatus (in IGFBP2- and $58 \mathrm{k}$-stained sections, respectively), already seen in RMS cell lines (see Figure 1, C and D). Hematoxylin was used as a counterstain. H: Plasma levels of IGFBP2 evaluated by ELISA assay are significantly higher in patients with RMS ( $\left.{ }^{*} P<0.001\right)$ versus healthy controls (CTRs). I: Plasma levels of IGFBP2 in translocation-negative RMS are significantly higher than in translocation-positive RMS. J: The plasma level of IGFBP2 is markedly higher $(P=0.05)$ in the group of patients with RMS who have advanced stage tumors (IRS stage IV). Box, interquartile range; center bar, median; whiskers, data range; and lines, outliers.

and D). This pattern mimics what we observed in RMS cell lines. Moreover, the staining of the 58k Golgi marker was superimposable to the signals of IGFBP2 antibody, confirming that IGFBP2 localized and accumulated in the Golgi apparatus of RMS cells in vivo (Figure 5, E-G). Overall, the expression and staining patterns of IGFBP2 differed between PAXIFKHR-positive and PAXIFKHRnegative patients with ARMS (Figure 5, B-D).

\section{Elevated IGFBP2 in Plasma Correlates to RMS Severity}

To test whether IGFBP2 protein was present in the plasma of patients with RMS and to assess whether its concentration was associated with aggressiveness, we used ELISA assays to detect plasma IGFBP2 in 41 patients with RMS before any therapy and in 15 healthy subjects as controls. Plasma levels of IGFBP2 were significantly higher in patients with RMS than in controls: median levels of $362.42 \mathrm{ng} / \mathrm{mL}$ in RMS patient samples and $60.11 \mathrm{ng} / \mathrm{mL}$ in controls $(P<0.001$, Figure $5 \mathrm{H})$. Moreover, we found that the IGFBP2 plasma level varies significantly between $P A X / F K H R$ fusion-positive and $P A X$ FKHR fusion-negative patients $(P=0.030$, Figure 5l).

To assess whether IGFBP2 correlated with RMS severity, we compared IGFBP2 plasma levels of nonmetastatic with metastatic RMS based on the Intergroup Rhabdomyosarcoma Study (IRS) grouping. Comparing nonmetastatic (IRS I-II-II) with metastatic (IRS IV) patients with RMS, we found that IGFBP2 levels were significantly higher in group IV patients with advanced-stage tumors $(P=0.05)$, demonstrating a positive correlation between IGFBP2 and tumor invasiveness (Figure 5J). Moreover, an analysis of variance multiway analysis was performed to evaluate if the combination of IRS group and the presence of the PAXIFKHR fusion gene were related to IGFBP2 plasma level. This analysis confirmed and validated that an elevated plasma concentration of IGFBP2 positively correlated with higher aggressiveness of tumor $(P=0.024)$ and with PAX/FKHR-negative subtype $(P=0.001)$.

\section{Discussion}

Our previous studies 29,45 on the human RMS transcriptome indicated that IGFPB2 was one of the genes that may play an important role in the biological characteristics of this pediatric cancer because it is differentially expressed in different RMS subtypes. To analyze the IGFBP2-induced signaling pathway in RMS, we studied gene expression profiling of RMS cells undergoing forced inhibition of IGFBP2 expression. In the signature of these cells, we observed a significant deregulation of transcripts belonging to protein transport and Golgi vesicle-mediated transport. At the same time, RMS cells showed packaging of IGFBP2 in the Golgi apparatus that appeared morphologically altered.

These results were confirmed by immunogold labeling of ultrathin cryosections showing that, in RMS cells, IGFBP2 associates with unusual perinuclear Golgi structures that resemble enlarged vesicles. The Golgi luminal $\mathrm{Ca}^{2+}$ concentration and variations may be key controllers of the function of this organelle. ${ }^{38}$ By using a $\mathrm{Ca}^{2+}$-sensitive photoprotein to investigate the $\mathrm{Ca}^{2+}$ homeostasis in RMS cells, we showed a marked deregulation of the Golgi $\mathrm{Ca}^{2+}$ cycle, suggesting a functional alteration. Because depletion of $\mathrm{Ca}^{2+}$ from the Golgi organelle has 
several effects on the secretory pathway, ${ }^{43}$ we used the VSVG-GFP mutant protein to study protein transport. We found that the characteristic rearrangement of Golgi complex was associated with increased VSVG transport to the cell surface in RMS cells. Babiá et $\mathrm{al}^{46}$ observed that transformation of a murine cell line with the oncogenic $\mathrm{N}$-Ras caused a rearrangement of the Golgi complex into collapsed morphological features, similar to that caused by IGFBP2. Furthermore, in agreement with our findings, they reported an increase in protein transport from the trans-Golgi network to the cell surface, suggesting an alteration in membrane trafficking.

Our hypothesis is that IGFBP2 is produced in abnormal amounts and accumulates in atypical Golgi structures. Subsequently, the unusually high quantity of IGFBP2 moves from the Golgi apparatus to the cell surface, entering in a defective secretory pathway, as suggested by VSVG-GFP results. In cell tumor ultrathin sections, we observed that the organelle was rearranged only in part. RMS cells showed normal Golgi stacks, and this is expected given that the cells have an active secretion of proteins. However, cells also showed atypical Golgi structures that probably function as storage of an abnormal amount of secreted proteins and that could be responsible for the strong signal observed in immunofluorescence experiments.

Gene expression profiling of IGFBP2-silenced cells also revealed an alteration of transcripts involved in the regulation of the cell cycle and in cell migration and adhesion, such as MCMs and cyclin D1. The MCMs are a family of highly conserved proteins, playing an essential role in the early stages of eukaryotic genome replication. The requirement for MCM proteins in cycling cells and their absence in quiescent cells have led to their potential clinical application as proliferation markers, useful in cancer diagnosis. Microarray analyses and $\mathrm{IHC}$ studies ${ }^{47,48}$ have shown increased mRNA and protein levels of MCMs in many different tumor cells and in carcinomas with a clinically aggressive phenotype. Typically, cyclin D1 acts together with their CDK partners to control $G_{1}-S$-phase progression through the inactivation of retinoblastoma protein and the release of the E2F transcription factor. The protein is frequently overexpressed in a large spectrum of human cancers, such as breast, lung, and bladder cancers, in which it may contribute to tumorigenesis. ${ }^{49}$ We found that IGFBP2-silenced cells showed a significant, but not dramatic, decrease of the proliferation rate, paralleled by an enrichment of cells in the $G_{1}$ phase, probably because of weak involvement of IGFBP2 in this specific cellular process. Literature data $^{15,17}$ are conflicting regarding the role of IGFBP2 on cell cycle progression. Moreover, recent studies ${ }^{50}$ revealed a role of cyclin D1 in cell migration, correlating its overexpression with cellular metastasis. Cell migration is essential for the invasion of tumor cells into the surrounding tissues. This coordinated migration process leads to tumor metastasis. An important contribution to cell motility depends on several changes in actin cytoskeletal structures. ${ }^{51}$ Our microarray results confirmed that many transcripts involved in cytoskeleton remodeling are correlated to IGFBP2 expression.
Another interesting finding that supports a key role of IGFBP2 in the invasiveness of RMS cells is the deregulation of MMP2 as a consequence of IGFBP2 silencing. Several studies ${ }^{52}$ have shown that an increased level of MMP2 expression is associated with an aggressive phenotype and poor prognosis in various human cancers, indicating MMP2 as a biomarker useful for stratifying patients with cancer into different risk groups. Moreover, a gene expression analysis in gliomas revealed a consistent induction of MMP2 by IGFBP2. ${ }^{8}$ In our study, we demonstrated that IGFBP2 silencing in RMS cells affects migration and invasion.

Taken together, our results show that the strong silencing of IGFBP2 results in a complex phenotype and, therefore, we suggest that IGFBP2 may modulate an integrated network of genes involved in proliferation, cytoskeleton rearrangement, and tumor progression. This conclusion is further supported by our in vivo experiments demonstrating that stably IGFBP2-silenced cells showed reduced seeding ability in the lungs. Although we do not have sufficient experimental data to discuss a direct link between the accumulation of IGFBP2 in the Golgi apparatus, increase of IGFBP2 at the cell surface, and its prometastatic roles, we can speculate that the proinvasive effect is amplified by an alteration of Golgi protein trafficking.

To define the possible role of IGFBP2 in RMS in vivo, we determined IGFBP2 expression in tumor specimens. Only RMS fusion-negative patients were positive for IGFBP2 staining. Thus, IGFBP2 could reliably distinguish $P A X /$ FKHR-positive from PAXIFKHR-negative tumors and, consequently, may represent a useful marker in clinical practice. Furthermore, we confirmed a perinuclear IGFBP2 staining pattern in PAXIFKHR-negative tumor biopsy specimens that overlapped a Golgi marker distribution. Thus, IGFBP2 accumulation appears to also correlate with a morphological modification of the Golgi apparatus in vivo. The immunostaining pattern of IGFBP2 has been studied by Makawita et al, ${ }^{53}$ who assayed the level of all IGF pathway proteins in an RMS group of 29 patients belonging to different subtypes. They found an IGFBP2 expression pattern similar to our results but that focused on differences between ARMS and ERMS independently of the PAX3/FKHR fusion gene status. They reported that IGFBP2 did not differ significantly $(P=0.052)$ between the two major subgroups of RMS, although a study of a larger cohort of patients was warranted to draw definitive conclusions.

Finally, we tested IGFBP2 plasma levels in patients with RMS. The IGFBP2 plasma level was significantly higher than in healthy subjects, and IGFBP2 plasma levels discriminated between PAXIFKHR-positive and PAXI FKHR-negative patients, similar to IHC findings. Interestingly, when the levels of IGFBP2 were considered in relation to the aggressiveness of the tumor, we found that higher IGFBP2 levels were present in patients belonging to the high-risk group with metastatic disease at diagnosis. Further studies are needed to correlate the levels of IGFBP2 with different clinical characteristics of patients with RMS and with response to treatment. High plasma levels of IGFBP2 were associated with tumor progression 
and metastasis in a wide spectrum of tumors. ${ }^{14,17,54,55} \mathrm{~A}$ recent study ${ }^{56}$ revealed that plasma concentrations of IGFBP2 were elevated in patients with high-grade glioma. Moreover, plasma levels of IGFBP2 and low levels of IGFBP3 at diagnosis correlated with a high risk of relapse or a lack of remission in childhood acute lymphoblastic leukemia. ${ }^{57}$ These studies disclose the involvement of IGFBP2 in tumorigenesis and may lead to the discovery of new and specific treatments. In fact, the heat shock protein-90 inhibitors, including the geldanamycin derivative 17-AAG, decrease plasma IGFBP2 in patients with cancer. ${ }^{19}$ It would be interesting to determine whether treatments of RMS-overexpressing IGFBP2 with such drugs would influence growth and differentiation of RMS cells. In conclusion, our results provide evidence that IGFBP2 is overexpressed in PAXIFKHR fusion-negative RMS and could promote cancer progression by augmenting cell invasiveness and cell proliferation. Moreover, we have identified IGFBP2 as a marker that may contribute to refine a clinical and biological classification of patients with RMS.

\section{Acknowledgments}

We thank Beniamina Pacchioni, Caterina Millino, and Barbara Celegato (University of Padova, Interdepartmental Research Center in Innovative Biotechnology, CRIBI Microarray Service MicroCribi) for microarray fabrication; and Prof. Carlo Tacchetti and MariaCristina Gagliani for electron microscopy studies performed at the Telethon Facility for electron microscopy, the MicroSCoBiO Research Center, and the Institute of Molecular Oncology Foundation (IFOM) and Ultrastructure, Genova, Italy.

\section{References}

1. Wheatcroft SB, Kearney MT: IGF-dependent and IGF-independent actions of IGF-binding protein-1 and -2: implications for metabolic homeostasis. Trends Endocrinol Metab 2009, 20:153-162

2. Firth SM, Baxter RC: Cellular actions of the insulin-like growth factor binding proteins. Endocr Rev 2002, 23:824-854

3. Frommer KW, Reichenmiller K, Schutt BS, Hoeflich A, Ranke MB, Dodt G, Elmlinger MW: IGF-independent effects of IGFBP-2 on the human breast cancer cell line Hs578T. J Mol Endocrinol 2006, 37: 13-23

4. Schutt BS, Langkamp M, Rauschnabel U, Ranke MB, Elmlinger MW: Integrin-mediated action of insulin-like growth factor binding protein-2 in tumor cells. J Mol Endocrinol 2004, 32:859-868

5. Russo VC, Schutt BS, Andaloro E, Ymer SI, Hoeflich A, Ranke MB, Bach LA, Werther GA: Insulin-like growth factor binding protein-2 binding to extracellular matrix plays a critical role in neuroblastoma cell proliferation, migration, and invasion. Endocrinology 2005, 146: 4445-4455

6. Pereira JJ, Meyer T, Docherty SE, Reid HH, Marshall J, Thompson EW, Rossjohn J, Price JT: Bimolecular interaction of insulin-like growth factor (IGF) binding protein-2 with alphavbeta3 negatively modulates IGF-I-mediated migration and tumor growth. Cancer Res 2004, 64:977-984

7. Fuller GN, Rhee CH, Hess KR, Caskey LS, Wang R, Bruner JM, Yung WK, Zhang W: Reactivation of insulin-like growth factor binding protein 2 expression in glioblastoma multiforme: a revelation by parallel gene expression profiling. Cancer Res 1999, 59:4228-4232

8. Wang $\mathrm{H}$, Shen W, Huang H, Hu L, Ramdas L, Zhou YH, Liao WS, Fuller GN, Zhang W: Insulin-like growth factor binding protein 2 enhances glioblastoma invasion by activating invasion-enhancing genes. Cancer Res 2003, 63:4315-4321

9. Wang GK, Hu L, Fuller GN, Zhang W: An interaction between insulinlike growth factor-binding protein 2 (IGFBP2) and integrin alpha5 is essential for IGFBP2-induced cell mobility. J Biol Chem 2006, 281: 14085-14091

10. Fukushima T, Tezuka T, Shimomura T, Nakano S, Kataoka H: Silencing of insulin-like growth factor-binding protein-2 in human glioblastoma cells reduces both invasiveness and expression of progressionassociated gene CD24. J Biol Chem 2007, 282:18634-18644

11. Song SW, Fuller GN, Khan A, Kong S, Shen W, Taylor E, Ramdas L, Lang FF, Zhang W: Ilp45, an insulin-like growth factor binding protein 2 (IGFBP-2) binding protein, antagonizes IGFBP-2 stimulation of glioma cell invasion. Proc Natl Acad Sci U S A 2003, 100:13970-13975

12. Moore LM, Holmes KM, Smith SM, Wu Y, Tchougounova E, Uhrbom L, Sawaya R, Bruner JM, Fuller GN, Zhang W: IGFBP2 is a candidate biomarker for Ink4a-Arf status and a therapeutic target for high-grade gliomas. Proc Natl Acad Sci U S A 2009, 106:16675-16679

13. Perks CM, Vernon EG, Rosendahl AH, Tonge D, Holly JM: IGF-II and IGFBP-2 differentially regulate PTEN in human breast cancer cells. Oncogene 2007, 26:5966-5972

14. Mehrian-Shai R, Chen CD, Shi T, Horvath S, Nelson SF, Reichardt JK, Sawyers CL: Insulin growth factor-binding protein 2 is a candidate biomarker for PTEN status and PI3K/Akt pathway activation in glioblastoma and prostate cancer. Proc Natl Acad Sci U S A 2007, 104:5563-5568

15. Dunlap SM, Celestino J, Wang H, Jiang R, Holland EC, Fuller GN, Zhang W: Insulin-like growth factor binding protein 2 promotes glioma development and progression. Proc Natl Acad Sci U S A 2007, 104:11736-11741

16. Degraff DJ, Aguiar AA, Sikes RA: Disease evidence for IGFBP-2 as a key player in prostate cancer progression and development of osteosclerotic lesions. Am J Transl Res 2009, 1:115-130

17. Lee EJ, Mircean C, Shmulevich I, Wang H, Liu J, Niemistö A, Kavanagh $\mathrm{JJ}$, Lee $\mathrm{JH}$, Zhang $\mathrm{W}$ : Insulin-like growth factor binding protein 2 promotes ovarian cancer cell invasion. Mol Cancer 2005, 4:7

18. Martin JL, Baxter RC: Expression of insulin-like growth factor binding protein-2 by MCF-7 breast cancer cells is regulated through the phosphatidylinositol 3-kinase/AKT/mammalian target of rapamycin pathway. Endocrinology 2007, 148:2532-2541

19. Eiseman JL, Guo J, Ramanathan RK, Belani CP, Solit DB, Scher HI, Ivy SP, Zuhowski EG, Egorin MJ: Evaluation of plasma insulin-like growth factor binding protein 2 and Her-2 extracellular domain as biomarkers for 17-allylamino-17-demethoxygeldanamycin treatment of adult patients with advanced solid tumors. Clin Cancer Res 2007. 13:2121-2127

20. So Al, Levitt RJ, Eigl B, Fazli L, Muramaki M, Leung S, Cheang MC Nielsen TO, Gleave M, Pollak M: Insulin-like growth factor binding protein-2 is a novel therapeutic target associated with breast cancer. Clin Cancer Res 2008, 14:6944-6954

21. Allander SV, Illei PB, Chen Y, Antonescu CR, Bittner M, Ladanyi M, Meltzer PS: Expression profiling of synovial sarcoma by cDNA microarrays: association of ERBB2, IGFBP2, and ELF3 with epithelial differentiation. Am J Pathol 2002, 161:1587-1595

22. Tschoep K, Kohlmann A, Schlemmer M, Haferlach T, Issels RD: Gene expression profiling in sarcomas. Crit Rev Oncol Hematol 2007, 63: $111-124$

23. Dagher R, Helman L: Rhabdomyosarcoma: an overview. Oncologist 1999, 4:34-44

24. Barr FG: Molecular genetics and pathogenesis of rhabdomyosarcoma. J Pediatr Hematol Oncol 1997, 19:483-491

25. Anderson J, Ramsay A, Gould S, Pritchard-Jones K: PAX3-FKHR induces morphological change and enhances cellular proliferation and invasion in rhabdomyosarcoma. Am J Pathol 2001, 159:10891096

26. Sorensen PH, Lynch JC, Qualman SJ, Tirabosco R, Lim JF, Maurer HM, Bridge JA, Crist WM, Triche TJ, Barr FG: PAX3-FKHR and PAX7-FKHR gene fusions are prognostic indicators in alveolar rhabdomyosarcoma: a report from the children's oncology group. J Clin Oncol 2002, 20:2672-2679

27. Keller C, Capecchi MR: New genetic tactics to model alveolar rhabdomyosarcoma in the mouse. Cancer Res 2005, 65:7530-7532

28. Davicioni E, Finckenstein FG, Shahbazian V, Buckley JD, Triche TJ, Anderson MJ: Identification of a PAX-FKHR gene expression signa- 
ture that defines molecular classes and determines the prognosis of alveolar rhabdomyosarcomas. Cancer Res 2006, 66:6936-6946

29. De Pitta C, Tombolan L, Albiero G, Sartori F, Romualdi C, Jurman G, Carli M, Furlanello C, Lanfranchi G, Rosolen A: Gene expression profiling identifies potential relevant genes in alveolar rhabdomyosarcoma pathogenesis and discriminates PAX3-FKHR positive and negative tumors. Int J Cancer 2006, 118:2772-2781

30. Charytonowicz E, Cordon-Cardo C, Matushansky I, Ziman M: Alveolar rhabdomyosarcoma: is the cell of origin a mesenchymal stem cell? Cancer Lett 2009, 279:126-136

31. Pfaffl MW: A new mathematical model for relative quantification in real-time RT-PCR. Nucleic Acids Res 2001, 29:e45

32. Livak KJ, Schmittgen TD: Analysis of relative gene expression data using real-time quantitative PCR and the $2^{-\Delta \Delta C T}$ Method. Methods 2001, 25:402-408

33. Saeed Al, Sharov V, White J, Li J, Liang W, Bhagabati N, Braisted J, Klapa M, Currier T, Thiagarajan M, Sturn A, Snuffin M, Rezantsev A, Popov D, Ryltsov A, Kostukovich E, Borisovsky I, Liu Z, Vinsavich A, Trush V, Quackenbush J: TM4: a free, open-source system for microarray data management and analysis. Biotechniques 2003, 34: 374-378

34. Tusher VG, Tibshirani R, Chu G: Significance analysis of microarrays applied to the ionizing radiation response. Proc Natl Acad Sci U S A 2001, 98:5116-5121

35. Saeed Al, Bhagabati NK, Braisted JC, Liang W, Sharov V, Howe EA, Li J, Thiagarajan M, White JA, Quackenbush J: TM4 microarray software suite. Methods Enzymol 2006, 411:134-193

36. Huang da W, Sherman BT, Stephens R, Baseler MW, Lane HC, Lempicki RA: DAVID gene ID conversion tool. Bioinformation 2008, 2:428-430

37. Edgar R, Domrachev M, Lash AE: Gene Expression Omnibus: NCBI gene expression and hybridization array data repository. Nucleic Acids Res 2002, 30:207-210

38. Pinton P, Pozzan T, Rizzuto R: The Golgi apparatus is an inositol 1,4,5-trisphosphate-sensitive $\mathrm{Ca} 2+$ store, with functional properties distinct from those of the endoplasmic reticulum. EMBO J 1998, 17:5298-5308

39. Pinton P, Rimessi A, Romagnoli A, Prandini A, Rizzuto R: Biosensors for the detection of calcium and pH. Methods Cell Biol 2007, 80:297325

40. Schiaffino MV, Tacchetti C: The ocular albinism type 1 (OA1) protein and the evidence for an intracellular signal transduction system involved in melanosome biogenesis. Pigment Cell Res 2005, 18:227233

41. Dull T, Zufferey R, Kelly M, Mandel RJ, Nguyen M, Trono D, Naldini L: A third-generation lentivirus vector with a conditional packaging system. J Virol 1998, 72:8463-8471

42. Misumi Y, Miki K, Takatsuki A, Tamura G, Ikehara Y: Novel blockade by brefeldin $\mathrm{A}$ of intracellular transport of secretory proteins in cultured rat hepatocytes. J Biol Chem 1986, 261:11398-11403
43. Presley JF, Cole NB, Schroer TA, Hirschberg K, Zaal KJ, LippincottSchwartz J: ER-to-Golgi transport visualized in living cells. Nature 1997, 389:81-85

44. Kuismanen E, Saraste J: Low temperature-induced transport blocks as tools to manipulate membrane traffic. Methods Cell Biol 1989, 32:257-274

45. Romualdi C, De Pittà C, Tombolan L, Bortoluzzi S, Sartori F, Rosolen A, Lanfranchi G: Defining the gene expression signature of rhabdomyosarcoma by meta-analysis. BMC Genomics 2006, 7:287

46. Babiá $T$, Ayala I, Valderrama $F$, Mato $E$, Bosch M, Santarén JF, Renau-Piqueras J, Kok JW, Thomson TM, Egea G: N-Ras induces alterations in Golgi complex architecture and in constitutive protein transport. J Cell Sci 1999, 112(Pt 4):477-489

47. Forsburg SL: Eukaryotic MCM proteins: beyond replication initiation. Microbiol Mol Biol Rev 2004, 68:109-131

48. Tachibana KE, Gonzalez MA, Coleman N: Cell-cycle-dependent regulation of DNA replication and its relevance to cancer pathology. J Pathol 2005, 205:123-129

49. Kim JK, Diehl JA: Nuclear cyclin D1: an oncogenic driver in human cancer. J Cell Physiol 2009, 220:292-296

50. Li Z, Wang C, Prendergast GC, Pestell RG: Cyclin D1 functions in cell migration. Cell Cycle 2006, 5:2440-2442

51. Oser M, Condeelis J: The cofilin activity cycle in lamellipodia and invadopodia. J Cell Biochem 2009, 108:1252-1262

52. Guo CB, Wang S, Deng C, Zhang DL, Wang FL, Jin XQ: Relationship between matrix metalloproteinase 2 and lung cancer progression. Mol Diagn Ther 2007, 11:183-192

53. Makawita S, Ho M, Durbin AD, Thorner PS, Malkin D, Somers GR: Expression of insulin-like growth factor pathway proteins in rhabdomyosarcoma: IGF-2 expression is associated with translocation-negative tumors. Pediatr Dev Pathol 2009, 12:127-135

54. Brady G, O'Regan E, Miller I, Ogungbowale A, Kapas S, Crean SJ: Serum levels of insulin-like growth factors (IGFs) and their binding proteins (IGFBPs), -1, -2, -3, in oral cancer. Int J Oral Maxillofac Surg 2007, 36:259-262

55. Shariat SF, Lamb DJ, Kattan MW, Nguyen C, Kim J, Beck J, Wheeler TM, Slawin KM: Association of preoperative plasma levels of insulinlike growth factor I and insulin-like growth factor binding proteins-2 and -3 with prostate cancer invasion, progression, and metastasis. $\mathrm{J}$ Clin Oncol 2002, 20:833-841

56. Lin Y, Jiang T, Zhou K, Xu L, Chen B, Li G, Qiu X, Jiang T, Zhang W, Song SW: Plasma IGFBP-2 levels predict clinical outcomes of patients with high-grade gliomas. Neuro Oncol 2009, 11:468476

57. Vorwerk P, Mohnike K, Wex H, Rohl FW, Zimmermann M, Blum WF, Mittler U: Insulin-like growth factor binding protein-2 at diagnosis of childhood acute lymphoblastic leukemia and the prediction of relapse risk. J Clin Endocrinol Metab 2005, 90:3022-3027 